\title{
Sensitive assay for measurement of volatile borneol, isoborneol, and the metabolite camphor in rat pharmacokinetic study of Borneolum (Bingpian) and Borneolum syntheticum (synthetic Bingpian)
}

\author{
Chen CHENG ${ }^{1}$, Xin-wei LIU ${ }^{1}$, Fei-fei DU ${ }^{1}$, Mei-juan $\mathrm{LI}^{1}$, Fang XU ${ }^{1}$, Feng-qing WANG ${ }^{1}$, Yang LIU $^{1, \$}$, Chuan $\mathrm{LI}^{1,2, *}$, Yan SUN ${ }^{1, *}$ \\ ${ }^{1}$ Shanghai Institute of Materia Medica, Chinese Academy of Sciences, Shanghai 201203, China; ${ }^{2}$ Institute of Chinese Materia Med- \\ ica, China Academy of Chinese Medical Sciences, Beijing 100700, China
}

\begin{abstract}
Aim: Both Borneolum (Chinese name Bingpian; dextrorotatory borneol) and Borneolum syntheticum (synthetic Bingpian; a mixture of optically inactive borneol and isoborneol) have been used for medicinal purposes in Chinese traditional medicine. The aim of this study was to develop a sensitive assay for measuring volatile ingredients borneol, isoborneol, and their metabolite camphor in pharmacokinetic study of Bingpian.

Methods: Rat plasma samples were prepared using liquid-liquid microextraction: $70 \mu \mathrm{L}$ of plasma sample (containing $125 \mathrm{nmol} / \mathrm{L}$ naphthalene as the internal standard) was extracted with $35 \mu \mathrm{L}$ of $n$-hexane. The resulting $n$-hexane extract ( $20 \mu \mathrm{L})$ was introduced into a gas chromatography/mass spectrometry system using programmable temperature vaporizing-based large-volume injection. The assay was validated to demonstrate its reliability for the intended use. Using this assay, pharmacokinetic studies of Bingpian, synthetic Bingpian, and Fufang-Danshen tablets (containing synthetic Bingpian) were conducted in rats.

Results: The extraction efficiency for the analytes and the internal standard from plasma was almost constant with decrease in $n$-hexane-to-plasma volume ratio, thus enabling a small volume of extracting solvent to be used for sample preparation, and enhancing the assay sensitivity. The lower quantification limit for measuring borneol, isoborneol, and camphor in plasma was $0.98 \mathrm{nmol} / \mathrm{L}$, which was 33-330 times more sensitive than those reported earlier for Bingpian and synthetic Bingpian. The applicability of the miniaturized liquid-liquid extraction technique could be extended to measure other volatile and nonvolatile medicinal compounds in biomatrices, which can be predicted according to the analytes' octanol/water distribution coefficient $(\log D)$ and acid dissociation constant $\left(\mathrm{p} K_{\mathrm{a}}\right)$.

Conclusion: This assay is sensitive, accurate and free of matrix effects, and can be applied to pharmacokinetic studies of Bingpian, synthetic Bingpian, and Bingpian-containing herbal products.
\end{abstract}

Keywords: pharmacokinetics; borneol; isoborneol; camphor; Bingpian; liquid-liquid microextraction; gas chromatography/mass spectrometry; large-volume injection

Acta Pharmacologica Sinica (2013) 34: 1337-1348; doi: 10.1038/aps.2013.86; published online 26 Aug 2013

\section{Introduction}

Many important bioactive constituents of herbal medicines are volatile compounds ${ }^{[1-4]}$, which are commonly analyzed using hyphenated gas chromatography (GC) techniques ${ }^{[5,6]}$. To understand the contribution of these compounds to the medicinal effects of the herbal medicines containing them, it is

\footnotetext{
${ }^{\$}$ Visiting graduate student from Tianjin University of Traditional Chinese Medicine.

* To whom correspondence should be addressed.

E-mail chli@simm.ac.cnn (Chuan LI);

sunyan@simm.ac.cn (Yan SUN)

Received 2013-05-04 Accepted 2013-06-05
}

important to investigate the pharmacokinetics and disposition of the volatile ingredients. However, associated pharmacokinetic (PK) studies are often hampered by assay failure in the measurement of such herbal compounds and their volatile metabolites in complex biomatrices. Liquid-liquid extraction is often used for GC-based analysis, which involves the transfer of volatile analytes from the aqueous biological sample into a water-immiscible organic solvent. Because of the column's low loading capacity (normally 1-2 $\mu \mathrm{L}$ ), only a small portion of the organic extract is allowed to be introduced directly into the GC capillary column, which is unfavorable for the assay sensitivity. Conventional concentration of the organic extract 
under either reduced pressure or a stream of nitrogen gas can lead to serious evaporative losses of the volatile analytes and, in turn, result in unacceptable assay accuracy and the loss of sensitivity. To support trace analysis, Vogt developed a programmable temperature vaporizing (PTV) injector for largevolume injection (LVI) of an organic sample (up to $250 \mu \mathrm{L}$ ) in capillary GC, which involves a quick solvent vent technique ${ }^{[7]}$. Successful implementation of PTV-based LVI requires the use of an organic solvent that has a sufficiently lower boiling point (bp) than that of the analyte (typically $>100^{\circ} \mathrm{C}$ ). Additionally, the solvent vapor needs to be minimized to avoid its substantial transfer to the vacuum system of the mass spectrometer. Furthermore, the solvent venting also needs to be stopped shortly before the completion of solvent evaporation because loss of the volatile analyte occurs primarily with the evaporation of the last few microliters of solvent ${ }^{[8]}$.

Borneolum (prepared from either Dryobalanops aromatica or Cinnamonum camphora) and Borneolum syntheticum (synthetically produced from turpentine oil) are used in Chinese traditional medicine under the name "Bingpian" ${ }^{[9,10]}$. Borneolum is dextrorotatory borneol (endo-1,7,7-trimethyl-bicyclo[2.2.1] heptan-2-ol) (Figure 1), which is a bicyclic monoterpene alco-
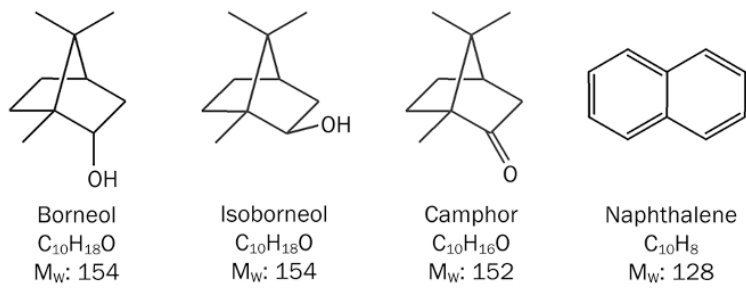

$M_{w}: 128$<smiles>N#[W+]#[W]OC(=O)O</smiles>

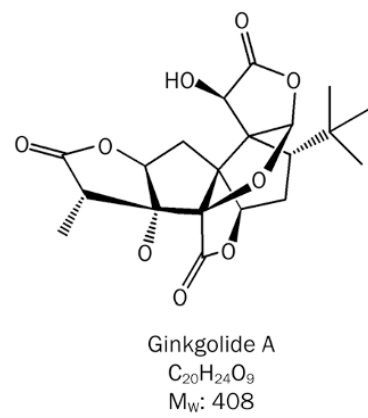

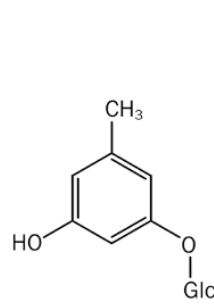

Orcinol glucoside $\mathrm{C}_{13} \mathrm{H}_{18} \mathrm{O}_{7}$ $\mathrm{M}_{\mathrm{w}}: 286$

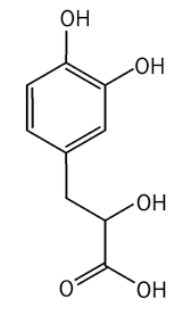

Tanshinol $\mathrm{C}_{9} \mathrm{H}_{10} \mathrm{O}_{5}$ $\mathrm{M}_{\mathrm{w}}: 198$

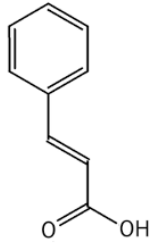

Cinamic acid $\mathrm{C}_{9} \mathrm{H}_{8} \mathrm{O}_{2}$ $\mathrm{M}_{\mathrm{w}}: 148$
Figure 1. Chemical structures of borneol, isoborneol, camphor, naphthalene, quercetin, ginkgolide $\mathrm{A}$, orcinol glucoside, tanshinol, and cinnamic acid. hol, whereas Borneolum syntheticum (also called synthetic Bingpian) is a mixture of optically inactive borneol and isoborneol (exo-1,7,7-trimethyl-bicyclo[2.2.1] heptan-2-ol). Bingpian and synthetic Bingpian exert medicinal actions, including restoring consciousness, removing heat, and relieving pain. Either Bingpian or synthetic Bingpian are commonly used as an ingredient in many Chinese combination herb therapies for treating cardiovascular and cerebrovascular diseases. Borneol and isoborneol have been reported to have a variety of in vitro pharmacological activities, including vasorelaxant ${ }^{[11]}$, anticoagulant $t^{[12]}$, neuroprotective ${ }^{[13,14]}$, sedative, and analgesic properties ${ }^{[15,16]}$. In addition, Bingpian and synthetic Bingpian have attracted much attention because of its possible enhancement of the oral bioavailability of other drugs and medicinal herbal compounds $\mathrm{s}^{[17,18]}$, and the passage across the blood brain barrier $^{[19-21]}$. Borneol can be oxidized to camphor (1,7,7-trimethylbicyclo[2.2.1]heptan-2-one), which has been observed in mice, rats, and rabbits receiving an oral dose of either Bingpian or synthetic Bingpian ${ }^{[22]}$. Camphor is believed to be poisonous when ingested in large quantities and can cause seizures, confusion, irritability, and neuromuscular hyperactivity ${ }^{[23]}$.

As part of our ongoing pharmacokinetic study of FufangDanshen-Fang ${ }^{[24-26]}$, a cardiovascular herb combination containing Salvia miltiorrhiza roots (Danshen), Panax notoginseng roots (Sanqi), and Bingpian, we developed a sensitive bioanalytical assay for the measurement of plasma concentrations of borneol, isoborneol, and their metabolite camphor. Several other assays have been reported for measurement of borneol and isoborneol in biomatrices using either GC-mass spectrometer $^{[27,28]}$ or GC-flame ionization detector ${ }^{[29-33]}$. However, these assays lack sensitivity and/or accuracy for one of two reasons: 1) only a small portion of the organic sample extract was introduced into the GC capillary columns, or 2) the evaporative concentration of the organic extract was used for the sample clean-up. High sensitivity was achieved for our newly developed assay by using a liquid-liquid microextraction technique working in concert with an optimal PTV-based LVI of the organic extract, which led to significantly increased amounts of the analytes from the plasma sample being applied to GCmass spectrometry-based analysis. To our knowledge, this is the first method of liquid-liquid microextraction combined with PTV-based LVI that has been developed for the measurement of plasma concentrations of volatile herbal compounds.

\section{Materials and methods Chemicals and materials}

Analytical reference standards of ( \pm )-borneol (bp 212-214 ${ }^{\circ} \mathrm{C}$ ), ( \pm )-isoborneol $\left(212-214^{\circ} \mathrm{C}\right),( \pm)$-camphor $\left(204^{\circ} \mathrm{C}\right)$, naphthalene $\left(218^{\circ} \mathrm{C}\right)$, quercetin, ginkgolide $\mathrm{A}$, tanshinol (sodiated form), and cinnamic acid were obtained from the National Institutes for Food and Drug Control (Beijing, China). Orcinol glucoside was kindly donated by Professor Jijun CHEN from Kunming Institute of Botany, the Chinese Academy of Sciences (Kunming, China). The purity of these compounds was greater than $98 \%$. HPLC-grade organic solvents were obtained from Sinopharm Chemical Reagent Co, Ltd (Shanghai, China). 
HPLC-grade water was prepared with an in-house Millipore Milli-Q Integral 3 cabinet water purifying system (Bedford, MA, USA).

Bingpian (D. aromatica) and synthetic Bingpian for animal studies were obtained from Shanghai Huayu Chinese Herbs Co, Ltd (Shanghai, China). The Bingpian contained only borneol, which comprised $96.4 \%$ of the drug. The synthetic Bingpian contained both borneol and isoborneol, which comprised $62.1 \%$ and $37.6 \%$ of the drug, respectively. Fufang-Danshen tablets (Chinese SFDA ratification No Z31020478; Shanghai Leiyunshang Pharmaceutical Co, Ltd, Shanghai, China) contained Danshen, Sanqi, and synthetic Bingpian. The herbal tablets (0.32 g each) contained borneol (3.72 mg/tablet) and isoborneol (1.98 mg/tablet), which were standardized to contain $\geq 0.2 \mathrm{mg}$ tanshinone $\mathrm{II}_{\mathrm{A}} /$ tablet and $\geq 5.0 \mathrm{mg}$ salvianolic acid B/tablet. Blank plasma was obtained from normal SpragueDawley rats receiving no drug treatment. All animal experiments were approved by the Institutional Animal Care and Use Committee (IACUC) at the Shanghai Institute of Materia Medica (Shanghai, China).

\section{GC-MS measurement of borneol, isoborneol, and camphor}

A Trace GC Ultra Gas Chromatograph (Thermo Fisher Scientific, Milan, Italy) was coupled to a Trace DSQ II single quadrupole mass spectrometer (Thermo Fisher Scientific, Austin, TX, USA). Aliquots $(20 \mu \mathrm{L})$ of $n$-hexane extract were introduced into a PTV injector with a glass sintered deactivated liner (Part № 45322060; 1.2 mm ID, $2.75 \mathrm{~mm}$ OD, 120 mm length, $135 \mu \mathrm{L}$ theoretical volume) in the LVI mode at an injection temperature of $60^{\circ} \mathrm{C}$, an injection time of $0.2 \mathrm{~min}$, a helium gas flow rate of $20 \mathrm{~mL} / \mathrm{min}$, a transfer heating rate of $14.5^{\circ} \mathrm{C} / \mathrm{s}$, a transfer temperature of $280^{\circ} \mathrm{C}$, and a splitless time of $1 \mathrm{~min}$. Subsequently, the cleaning temperature was increased to and maintained at $320^{\circ} \mathrm{C}$ for $8 \mathrm{~min}$ at a helium gas flow rate of $300 \mathrm{~mL} / \mathrm{min}$ to clean any remaining impurities. The chromatographic separation was achieved on a TR-5MS capillary column (30 m×0.25 mm ID; Thermo Fisher Scientific, Cheshire, UK) coated with $5 \%$ phenyl polysilphenylenesiloxane $(0.25 \mu \mathrm{m}$ film thickness), and the helium carrier gas (99.999\% purity) was delivered at a rate of $1.5 \mathrm{~mL} / \mathrm{min}$. The following GC temperature program was used: $60^{\circ} \mathrm{C}(0-2 \mathrm{~min})$, $60^{\circ} \mathrm{C}$ to $132^{\circ} \mathrm{C}\left(2-11 \mathrm{~min}\right.$ at $\left.8^{\circ} \mathrm{C} / \mathrm{min}\right), 132^{\circ} \mathrm{C}$ to $240^{\circ} \mathrm{C}(11-12$ $\min$ at $\left.108^{\circ} \mathrm{C} / \mathrm{min}\right), 240^{\circ} \mathrm{C}(12-14 \mathrm{~min})$, and $240^{\circ} \mathrm{C}$ to $60^{\circ} \mathrm{C}$ (14-17 $\mathrm{min}$ at $\left.-60^{\circ} \mathrm{C} / \mathrm{min}\right)$. The mass spectrometry was operated in electron impact (EI) mode at $70 \mathrm{eV}$. The temperatures set for the transfer line and the ion source were identical, at $250^{\circ} \mathrm{C}$. Selected ion monitoring of borneol, isoborneol, camphor, and the internal standard naphthalene was achieved at $m / z$ 95, 95, 95, and 128, respectively. Matrix-matched calibration curves were constructed for borneol, isoborneol, and camphor (0.25-16000 nmol/L for each analyte) using weighted $(1 / \mathrm{X})$ linear regression of the analyte/internal standard peak area ratios $(\mathrm{Y})$ against the corresponding nominal plasma concentrations of the analytes $(X, \mathrm{nmol} / \mathrm{L})$. The plasma concentration of the internal standard was $125 \mathrm{nmol} / \mathrm{L}$.

\section{Liquid-liquid microextraction for plasma sample clean-up}

Thawed plasma samples $(60 \mu \mathrm{L})$ were spiked with $10 \mu \mathrm{L}$ of the internal standard solution and then extracted with $35 \mu \mathrm{L}$ of $n$-hexane in glass tubes by vortex mixing at $1600 \mathrm{r} / \mathrm{min}$ for $3 \mathrm{~min}$. After a short centrifugation, the supernatant organic extracts were aspirated into $100 \mu \mathrm{L}$ glass inserts of a small internal diameter (placed in $1.5 \mathrm{~mL}$ polypropylene microcentrifuge tubes) and centrifuged at $21000 \times g$ for $10 \mathrm{~min}$. After centrifugation, the inserts were carefully placed in $2 \mathrm{~mL}$ sampler vials, and aliquots $(20 \mu \mathrm{L})$ of the supernatants were used for GC-MS analysis.

\section{Determination of analyte solubility}

Borneol, isoborneol, camphor, and the internal standard naphthalene, as well as a variety of nonvolatile compounds (quercetin, ginkgolide A, orcinol glucoside, tanshinol, and cinnamic acid), were assessed for their solubility in phosphate buffered saline (PBS; pH 7.4) at $23^{\circ} \mathrm{C}$. In brief, a volume of $100 \mu \mathrm{L}$ of PBS was added into a $10 \mathrm{~mL}$ glass centrifuge tube containing approximately $50 \mathrm{mg}$ of solid test compound, and then the tube was sealed with parafilm. The suspension was sonicated for $10 \mathrm{~min}$ and vortexed at $1600 \mathrm{r} / \mathrm{min}$ for $5 \mathrm{~min}$, which was repeated twice to enhance compound dissolution. After cooling to $23^{\circ} \mathrm{C}$, a small amount of the solid compound was added into the tube to promote precipitation. The resealed tube was kept under constant agitation and sampled at 24, 32, and $48 \mathrm{~h}$. After centrifugation at $21000 \times g$ for $10 \mathrm{~min}$, the supernatant was diluted and measured by either GC-MS (for the volatile compounds) or LC-MS/MS (for the nonvolatile compounds). The compound solubility was established when equilibrium was achieved as determined by the constant concentrations measured with the two serial samples. A similar study was performed for the test compounds to assess their solubility in either $n$-hexane or ethyl acetate, except for tanshinol and cinnamic acid. The solubility of tanshinol in ethyl acetate was assessed by extracting the saturated aqueous solution of sodiated tanshinol with an equal volume of the organic solvent. The same procedure was performed to measure the solubility of cinnamic acid in ethyl acetate.

\section{Assessment of the effects of the organic solvent-plasma volume ratio on the extraction efficiency and analyte response}

Eighty microliters of rat plasma fortified with $200 \mathrm{nmol} / \mathrm{L}$ of borneol, isoborneol, camphor, or naphthalene were extracted in a glass tube with $20,40,80,160,320$, or $640 \mu \mathrm{L}$ of $n$-hexane to produce solvent-plasma volume ratios of $0.25,0.5,1,2,4$, and 8 , respectively. After vortex mixing and centrifugation, the $n$-hexane extract supernatant $(2 \mu \mathrm{L})$ was used for GC-MS analysis. The extraction efficiency was determined by division of the analyte response (peak area) of the $n$-hexane extract versus that of the control $n$-hexane solution at the same compound concentration. A similar procedure was also performed using ethyl acetate as the extracting solvent for these volatile compounds, as well as the nonvolatile compounds ginkgolide A, quercetin, orcinol glucoside, tanshinol, and cinnamic acid. In addition, tanshinol and cinnamic acid were further tested 
individually using plasma samples acidified with $1 \mathrm{~mol} / \mathrm{L}$ hydrochloric acid to adjust the $\mathrm{pH}$ to 1.2.

\section{Assessment of matrix effects on GC-MS-based assay}

The potential acute matrix-induced response enhancement $t^{[34,35]}$ was assessed using a post-extraction spike method ${ }^{[36,37]}$ for the PTV-based LVI involved in the GC-MS measurement of plasma levels of borneol, isoborneol, camphor, and the internal standard naphthalene. The matrix effects on the measurement of the analytes in plasma were examined by comparing the peak area of the test compounds between two different sample sets. In sample set 1 , the test compounds were dissolved in matrix-free $n$-hexane and analyzed at concentrations of 3.91, 250 , and $16000 \mathrm{nmol} / \mathrm{L}$, except for the internal standard at 125 $\mathrm{nmol} / \mathrm{L}$. In sample set 2, blank rat plasma samples obtained from five rats were extracted with a half volume of $n$-hexane, and the resulting extracts were spiked with the analytes (3.91, 250 , or $16000 \mathrm{nmol} / \mathrm{L})$ and the internal standard (125 nmol/L). Division of the mean peak area of sample set 2 versus sample set 1 would indicate the possibility of an enhanced response (absolute matrix effect). When the absolute matrix effect was greater than $120 \%$, additional variability of the peak area in sample set 2 versus that in sample set 1 would indicate the presence of a relative matrix effect.

A long-term study was implemented to assess the tolerance of the PTV injector and the GC capillary column with 100 successive injections ( $20 \mu \mathrm{L}$ for each injection) of plasma extract standard containing borneol, isoborneol, camphor, and the internal standard naphthalene $(250 \mathrm{nmol} / \mathrm{L}$ for each compound). The potential subchronic matrix effect was determined with regards to changes of the compound response (peak area), the column efficiency, the retention time, and the peak shape.

\section{GC-MS-based assay validation}

Assay validation was carried out according to the US FDA guidelines on bioanalytical method validation (http://www. fda.gov/cder/guidance/index.htm) to demonstrate that the newly developed bioanalytical method was reliable for its intended applications. The quality control samples were prepared from an independent weighing of the reference standards.

\section{Application of assay to pharmacokinetic studies and blood sampling in rats}

Male Sprague-Dawley rats ( $250 \mathrm{~g})$ were obtained from the Sino-British SIPPR/BK Animal Laboratory (Shanghai, China). The use of rats and study protocols was approved by the IACUC (Shanghai, China). For blood sampling, a polyurethane cannula was cannulated aseptically into the femoral artery of each rat under pentobarbital anesthesia. After regaining their preoperative weights, the femoral artery-cannulated rats were randomly assigned to five groups (three rats/group) and received a single oral dose of Bingpian at $20 \mathrm{mg}$ borneol $/ \mathrm{kg}$, synthetic Bingpian at $20 \mathrm{mg}$ borneol+isoborneol $/ \mathrm{kg}$, or Fufang-Danshen tablet preparation at $20 \mathrm{mg}$ borneol+isoborneol $/ \mathrm{kg}$ or a single intravenous dose of Bingpian at $5 \mathrm{mg}$ borneol/ $\mathrm{kg}$ or synthetic Bingpian at $5 \mathrm{mg}$ borneol+isoborneol $/ \mathrm{kg}$. For the oral administration, Bingpian, synthetic Bingpian, and Fufang-Danshen tablets were prepared separately by grounding and mixing them with $5 \%$ $(w / v)$ Tween- 80 to achieve concentrations of $1 \mathrm{mg}$ borneol/ $\mathrm{mL}$, $1 \mathrm{mg}$ borneol+isoborneol/mL, and $1 \mathrm{mg}$ borneol+isoborneol/ $\mathrm{mL}$, respectively. For the intravenous administration, grounded Bingpian and synthetic Bingpian were dissolved in a mixture containing $0.5 \%(w / v) ~ N, N$-dimethylacetamide, $9.5 \%$ $(w / v)$ cremophor EL, and $90 \%(v / v)$ saline to achieve a concentration of $1 \mathrm{mg}$ borneol/mL and $1 \mathrm{mg}$ borneol+isoborneol/ $\mathrm{mL}$, respectively. Serial blood samples $(130-150 \mu \mathrm{L} ; 0,5,15$, $30 \mathrm{~min}$, and 1, 2, 4, 6, 8, 10, 14, and $24 \mathrm{~h}$ ) were collected into heparinized tubes and centrifuged. The resulting plasma fractions were kept frozen at $-70^{\circ} \mathrm{C}$ until analysis. The plasma PK parameters were estimated using the non-compartmental model of the Kinetica 5.0 software (Thermo Fisher Scientific, Philadelphia, PA, USA).

\section{Results}

GC-MS-based measurement of borneol, isoborneol, and camphor and PTV-based LVI enhances assay sensitivity

In the EI-mass spectra (Figure 2), the molecular ions of borneol, isoborneol, and camphor $(\mathrm{m} / \mathrm{z} 154,154$, and 152, respectively) are present at a low tendency. Accordingly, the most abundant fragment ions at $\mathrm{m} / \mathrm{z} 95$ were chosen for the sensitive measurement of these compounds. In contrast, the most intense ion of the internal standard naphthalene was its molecular ion at $m / z 128$ rather than the fragment ions. To facilitate refocusing of all the measured compounds at the top of the capillary column, the initial temperature of the column oven was set to $60^{\circ} \mathrm{C}$, which was $9^{\circ} \mathrm{C}$ lower than the bp of $n$-hexane. This temperature was maintained for 2 min for complete splitless transfer and column equilibrium. As shown in Figure 2, the chromatographic peaks of borneol $\left(t_{R}, 9.22 \mathrm{~min}\right)$, isoborneol (9.05 $\mathrm{min})$, camphor $(8.75 \mathrm{~min})$, and naphthalene (9.57 $\mathrm{min})$ were completely separated from one another and shaped evenly under an optimal column oven heating rate of $8^{\circ} \mathrm{C} /$ $\min$.

To further increase assay sensitivity, PTV-based LVI (15-30 $\mu \mathrm{L}$; using the $\sim 135-\mu \mathrm{L}$ glass sintered deactivated liner) was optimized and compared with PTV-based splitless injection $(2 \mu \mathrm{L})$ and PTV-based delayed splitless injection $(5-15 \mu \mathrm{L})$. The important solvent split parameters for the PTV-based LVI were the injection temperature, the solvent split time, and the solvent split flow-rate; optimization was achieved on the basis of the separation of the solvent $n$-hexane from the most volatile compound camphor. In addition, the transfer heating rate, transfer temperature, and initial GC column temperature were also important because efficient transfer of the test compounds from the liner to the column was required after solvent elimination. As shown in Figure 3, the best result was obtained with the PTV-based LVI of $20 \mu \mathrm{L}$ of a standard $n$-hexane solution containing borneol, isoborneol, camphor, and naphthalene. Increasing the injection size to $30 \mu \mathrm{L}$ resulted in 

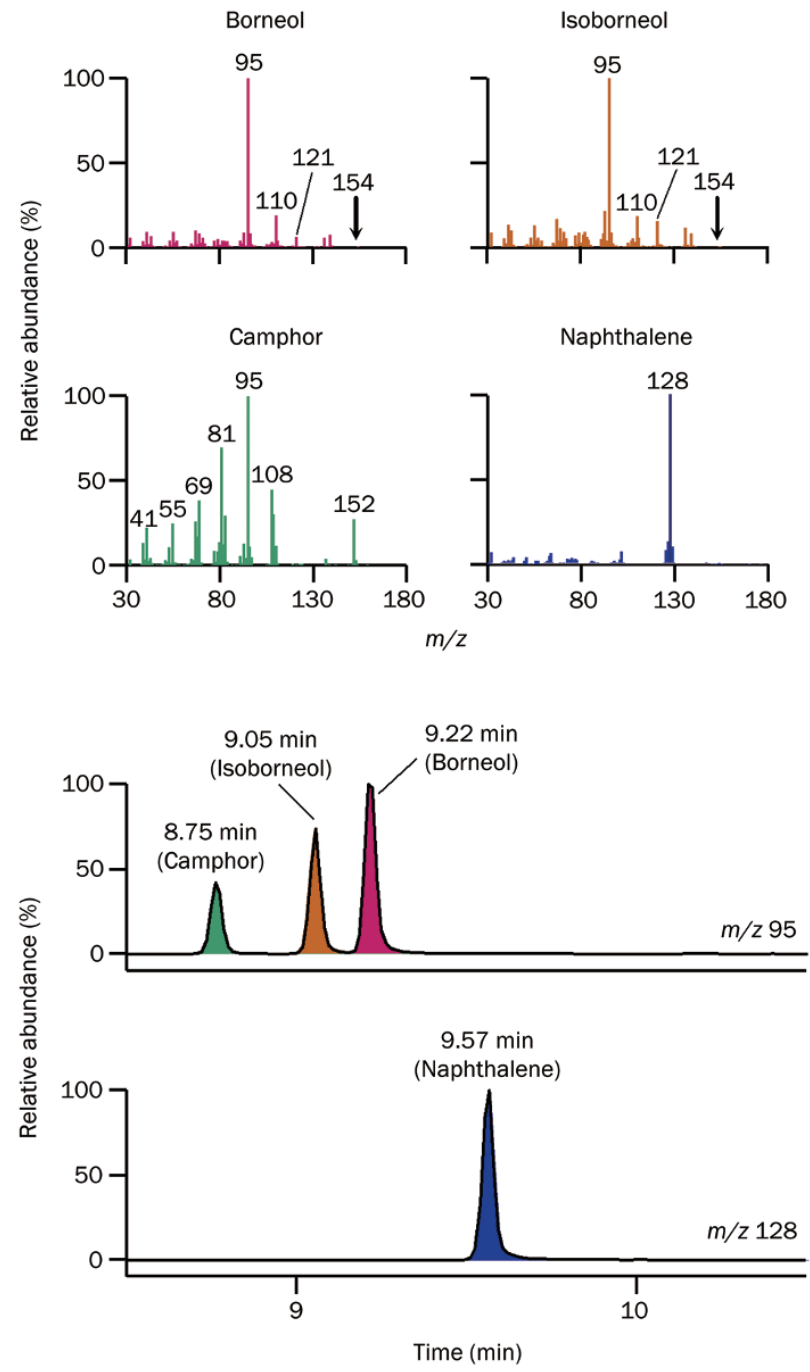

Figure 2. El-MS spectra of borneol, isoborneol, camphor, and the internal standard naphthalene. The GC separation was achieved for these compounds.

increased responses, but with considerable effects on the chromatographic peak shapes and vice versa. The unsuccessful implementation of PTV-based LVI over a volume of 20 $\mu \mathrm{L}$ was due to the insufficiently large differences in the $\mathrm{bp}$ between the measured compounds and the solvent $n$-hexane. However, a larger injection size (up to $50 \mu \mathrm{L}$ ) was successfully achieved when the more volatile solvent $n$-pentane $\left(\mathrm{bp} 36^{\circ} \mathrm{C}\right)$ was used instead of $n$-hexane $\left(69^{\circ} \mathrm{C}\right)$. Although $n$-pentane was a more favorable solvent for PTV-based LVI, it was rejected for the sample preparation (due to excessively low viscosity) and for the GC-MS analysis with a long waiting time (due to excessively high volatility).

\section{Liquid-liquid microextraction enhances assay sensitivity}

Although $n$-hexane is an efficient solvent for extraction of borneol, isoborneol, camphor, and the internal standard naphthalene, evaporative losses of these volatile compounds when extracting from plasma occur upon the subsequent dry-down step. For traditional liquid-liquid extraction, the extracting solvent is often used in a solvent-to-sample volume ratio ranging from 3 to 10 . The use of a large volume of extracting solvent is supposed to enhance the extraction efficiency. However, excessive solvent levels in this extraction method have a considerable dilution effect, i.e., the analyte concentration in the organic extract is lower than that in the pre-extracted aqueous sample. The application of such an organic extract (without any evaporative reduction) to GC-based analysis will result in decreased assay sensitivity. In the current study, we investigated the effect of the organic solvent-to-plasma volume ratio on the liquid-liquid extraction efficiency. As shown in Figure 4A, the extraction recoveries of borneol, isoborneol, camphor, and naphthalene from plasma using $n$-hexane as the solvent were almost constant with the decreasing $n$-hexaneto-plasma volume ratio. This consistency enabled the use of a small volume of extracting solvent for sample preparation to enhance the assay sensitivity by counteracting the aforementioned dilution effect, which was referred to as "liquid-liquid microextraction". For ease of operation, a small $n$-hexaneto-plasma volume ratio of 0.5 was chosen for preparation of the plasma samples $(70 \mu \mathrm{L})$ to ensure an enriched level of test compounds in the organic phase. Aside from the enhancement of assay sensitivity, this newly developed liquid-liquid microextraction method had other advantages, including organic solvent economy, environmental friendliness, and improved assay throughput.

To extend the application of the liquid-liquid microextraction method, ethyl acetate was also tested as a solvent for recovering borneol, isoborneol, camphor, and naphthalene from plasma. The results suggested that the performance of ethyl acetate for the compound extraction was similar to that of $n$-hexane. Although the relatively high $\mathrm{bp}\left(77^{\circ} \mathrm{C}\right)$ is unfavorable for the PTV-based LVI used in the current study, ethyl acetate is commonly used in sample preparation for many nonvolatile compounds. Figure $4 \mathrm{~B}$ shows the results of the ethyl acetate-based liquid-liquid extraction of several nonvolatile medicinal herbal compounds from plasma. The extraction efficiency was high for quercetin and ginkgolide $\mathrm{A}$ in an ethyl acetate-to-plasma volume ratio-independent manner. However, the extraction of orchinol glucoside, tanshinol, and cinnamic acid was significantly dependent on the ethyl acetate volume used; thus a large volume of the solvent was needed for high extraction recovery. The observed inconsistency in extraction performance appeared to be related to the organic solvent-to-water solubility ratios $\left(S_{\mathrm{O}} / S_{\mathrm{W}}\right.$ ratios) of the test compounds (Table 1). When the $\mathrm{pH}$ value of the aqueous phase was 7.4, the measured solubility ratios of borneol, isoborneol, camphor, naphthalene, quercetin, and ginkgolide A were high (122-9435; using $n$-hexane or ethyl acetate as the organic solvent), but those of orchinol glucoside, tanshinol, and cinnamic acid were very low (0.0006-0.137; using ethyl acetate as the organic solvent). These results could be predicted because the calculated $\log D$ values ( $\mathrm{pH} 7$ ) of the compounds were well correlated with their measured solubility ratios (Table 1). The 

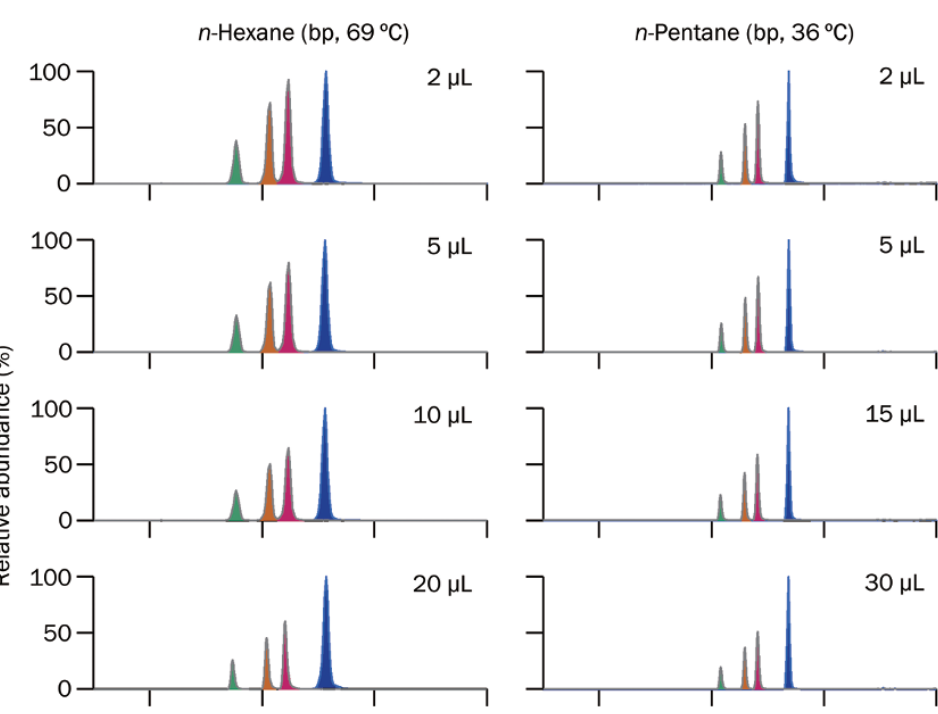

PTV-based sample

introduction technique

Splitless injection mode

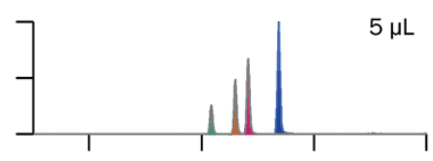

Delayed splitless injection mode

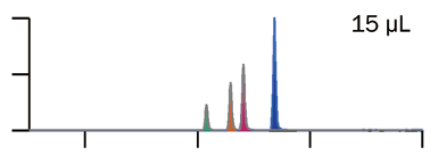

Delayed splitless injection mode

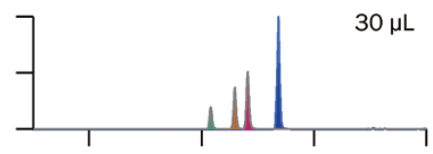

Large volume injection mode

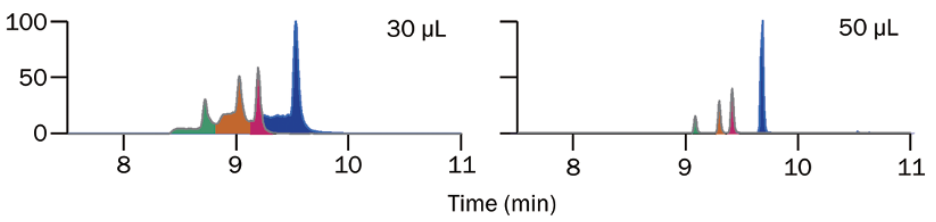

Large volume injection mode
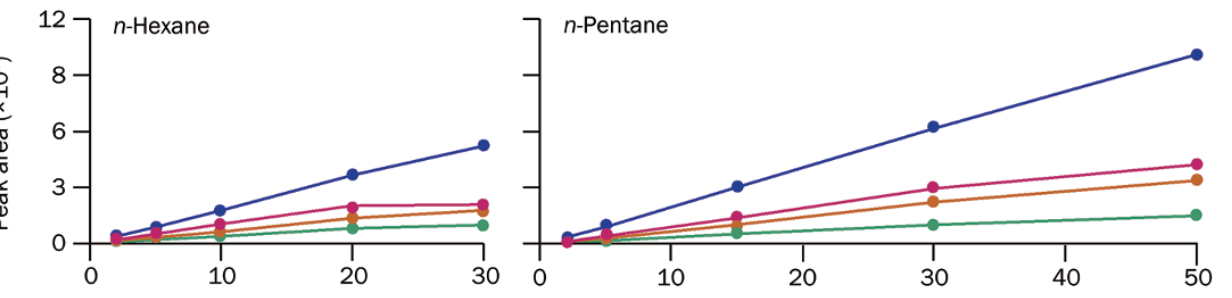

Borneol

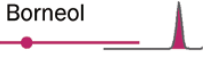

Isoborneol
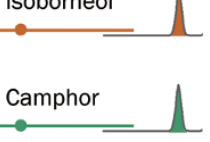

Naphthalene

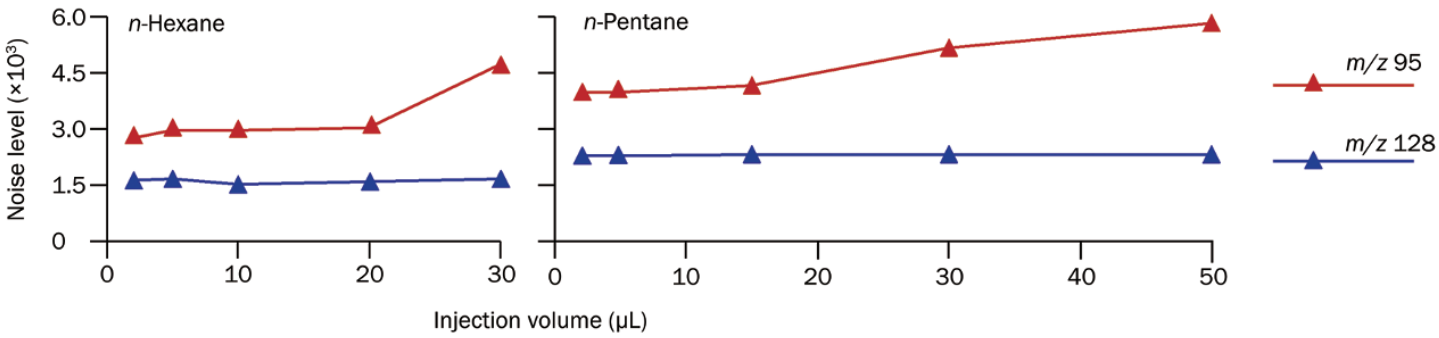

Figure 3. Comparative GC-MS chromatograms for the simultaneous measurement of borneol (bp, $212-214^{\circ} \mathrm{C}$ ), isoborneol $\left(212-214^{\circ} \mathrm{C}\right)$, camphor $\left(204^{\circ} \mathrm{C}\right)$, and naphthalene $\left(218^{\circ} \mathrm{C}\right)$ in either $n$-hexane $\left(69^{\circ} \mathrm{C}\right)$ or $n$-pentane $\left(36^{\circ} \mathrm{C}\right)$ under different PTV modes with various injection volumes. The signal intensities (peak areas) of the test compounds increased significantly as the injection volume increased from 2 to $20 \mu \mathrm{L}$ for $n$-hexane and from 2 to 50 $\mu \mathrm{L}$ for $n$-pentane, but the noise levels (measured at $\mathrm{m} / \mathrm{z} 95$ and $\mathrm{m} / \mathrm{z} 128$ ) did not change substantially.

$\log D$ values ( $\mathrm{pH}$ 7) of borneol, isoborneol, camphor, naphthalene, quercetin, and ginkgolide A ranged from -0.14 to 3.36, which were greater than those of orchinol glucoside, tanshinol, and cinnamic acid (-4.73 to -0.28$)$, with a $\log D$ value of $>-0.2$ serving as the threshold. Tanshinol and cinnamic acid are weak acids with low ionization constants $\left(\mathrm{pK}_{\mathrm{a}}\right)$ of 3.3 and 4.5, respectively. Liquid-liquid extraction efficiency is significantly affected by the existing state of the test compound in the aqueous phase because the compound in either its ionized form or molecular form favors the aqueous phase or the organic phase, respectively. Accordingly, plasma samples that were spiked with either tanshinol or cinnamic acid were acidified with $1 \mathrm{~mol} / \mathrm{L}$ hydrochloric acid to a $\mathrm{pH}$ of 1.2. The acidification resulted in increased ethyl acetate-based extraction efficiency for cinnamic acid but not for tanshinol (Figure 4C). As shown in Table 1, the effect of acidification on the enhanced extraction efficiency appeared to be predictable by comparing the $\log D$ values ( $\mathrm{pH} 7$ and $\mathrm{pH} 1$ ) of the compounds. The $\log D$ values ( $\mathrm{pH} 7$ and $\mathrm{pH} 1$ ) of cinnamic acid were -0.38 to -1.77 and 1.21 to 2.16 , respectively, whereas those of tanshinol were -3.77 to 
Table 1. Physicochemical properties of borneol, isoborneol, camphor, and naphthalene, as well as those of quercetin, ginkgolide A, orcinol glucoside, tanshinol, and cinnamic acid.

\begin{tabular}{|c|c|c|c|c|c|c|c|c|}
\hline \multirow[t]{2}{*}{ Compound } & \multicolumn{2}{|c|}{ Measured solubility (mg/mL) } & \multirow[t]{2}{*}{$\mathrm{S}_{\mathrm{w}} / \mathrm{S}_{0}$} & \multirow[t]{2}{*}{$\mathrm{p} K_{\mathrm{a} 1}$} & \multicolumn{2}{|c|}{$\log D$ by $A C D$} & \multicolumn{2}{|c|}{ Log $D$ by Pallas } \\
\hline & $S_{W}$ & $S_{0}$ & & & $\mathrm{pH}=1$ & $\mathrm{pH}=7$ & $\mathrm{pH}=1$ & $\mathrm{pH}=7$ \\
\hline \multicolumn{9}{|c|}{ Organic solvent: $\mathrm{n}$-hexane } \\
\hline Borneol & 0.71 & 87 & 122 & $>14$ & 2.55 & 2.55 & 3.00 & 3.00 \\
\hline Isoborneol & 0.69 & 88 & 127 & $>14$ & 2.55 & 2.55 & 3.00 & 3.00 \\
\hline Camphor & 1.84 & 347 & 189 & $>14$ & 2.09 & 2.09 & 2.92 & 2.92 \\
\hline Naphthalene & 0.023 & 171 & 7435 & $>14$ & 3.36 & 3.36 & 3.12 & 3.12 \\
\hline \multicolumn{9}{|c|}{ Organic solvent: ethyl acetate } \\
\hline Borneol & 0.71 & 315 & 444 & - & - & - & - & - \\
\hline Isoborneol & 0.69 & 513 & 743 & - & - & - & - & - \\
\hline Camphor & 1.84 & 698 & 379 & - & - & - & - & - \\
\hline Naphthalene & 0.023 & 217 & 9435 & - & - & - & - & - \\
\hline Quercetin & 0.007 & 17 & 2414 & 8.8 & 1.99 & 1.99 & 1.85 & 1.84 \\
\hline Ginkgolide A & 0.22 & 53.0 & 241 & 11.3 & -0.04 & -0.04 & -0.14 & -0.14 \\
\hline Orcinol glucoside & 342 & 5.0 & 0.01 & 9.8 & -0.9 & -0.9 & -0.75 & -0.75 \\
\hline Tanshinol & 297 & 0.019 & 0.00006 & 3.3 & -1.15 & -4.73 & -0.28 & -3.77 \\
\hline Cinnamic acid & 25.2 & 3.46 & 0.137 & 4.5 & 1.21 & -1.77 & 2.16 & -0.38 \\
\hline
\end{tabular}

$\mathrm{S}_{\mathrm{w}}$, water solubility at $\mathrm{pH}$ 7.4. $\mathrm{S}_{0}$, solubility in the organic solvent $n$-hexane or ethyl acetate. $\mathrm{pK}_{\mathrm{a} 1}$ and $\log D$ values were calculated using $A C D / a q u e o u s$ solubility v8.02 via the ACD/I-Lab service (Advanced Chemistry Development Inc, Toronto, Canada). LogD was also calculated using Pallas software (Pallas 3.7.1.1; CompuDrug International, Sedona, AZ, USA).

-4.73 and -0.28 to -1.15 , respectively.

\section{Assay reliability and sensitivity}

The potential acute matrix-induced response enhancement was assessed during assay development. As a result, the matrix components from the $n$-hexane-extracted plasma samples had a negligible influence on the measurement of borneol, isoborneol, camphor, and the internal standard naphthalene, demonstrating absolute matrix effects of $91.5 \%-104 \%$, $93.3 \%-109 \%, 89.6 \%-107 \%$, and $103 \%$, respectively. Accordingly, calculation of the relative matrix effects was unnecessary. As shown in Table 2, the compound responses and the chromatographic behaviors (eg, column efficiency, retention times, and peak shapes) did not change significantly during and after 100 successive injections of the plasma extract standard, indicating good tolerance of the PTV injector and the GC column for long-term use with biomatrix samples.

The analytes borneol, isoborneol, camphor, and the internal standard naphthalene were stable under analytical conditions mimicking those experienced by real plasma samples during an assay run. The calibration curves for the measurement of the analytes exhibited good linear ranges from 0.98 to $16000 \mathrm{nmol} / \mathrm{L}$ with correlation coefficients $>0.99$. As shown in Table 3, the within-run $(n=5)$ and between-run $(n=3)$ assay precision, assessed at the nominal plasma concentrations 0.98 , 250 , and $16000 \mathrm{nmol} / \mathrm{L}$, were reliable $(4.5 \%-9.6 \%$ for borneol, $5.9 \%-9.0 \%$ for isoborneol, and $3.1 \%-7.2 \%$ for camphor), and the associated assay accuracies were also satisfactory (90.0\%-111\% for borneol, $94.0 \%-109 \%$ for isoborneol, and $98.5 \%-113 \%$ for camphor). Accordingly, the lower quantifica- tion limit of $0.98 \mathrm{nmol} / \mathrm{L}$ was acceptable for the measurement of borneol, isoborneol, and camphor in plasma. To the best of our knowledge, the sensitivity of our newly developed assay is notably higher than that reported for the measurement of the monoterpene alcohols in plasma $(32.5-325 \mathrm{nmol} / \mathrm{L})^{[27-33]}$.

Application of the novel assay in the pharmacokinetic study of Bingpian, synthetic Bingpian, and Fufang-Danshen tablets

The pharmacokinetic study of Bingpian, synthetic Bingpian, and the synthetic Bingpian-containing phytopharmaceutical product Fufang-Danshen tablets in rats is an ideal application of the newly developed assay. Figure 5 depicts the plasma level-time profiles of borneol, isoborneol, and their metabolite camphor; the associated plasma pharmacokinetic parameters are summarized in Table 4 . The oral bioavailability $(F)$ of borneol was low $(8.3 \%-14.5 \%$ for Bingpian, $11.9 \%-14.0 \%$ for synthetic Bingpian, and 10.9\%-17.8\% for the Fufang-Danshen tablets). The $F$ values of isoborneol were also low $(2.0 \%-4.9 \%$ for synthetic Bingpian and $4.8 \%-12.7 \%$ for the Fufang-Danshen tablets). The metabolism from borneol and isoborneol to camphor appeared to contribute to the first-pass elimination of the monoterpene alcohols. This was indicative of the mean ratio

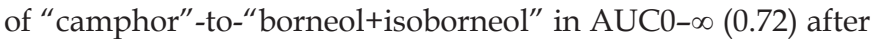
oral administration of synthetic Bingpian was greater than the ratio (0.29) after intravenous administration of the same drug. The mean ratio of "camphor"-to-"borneol" after oral ingestion of Bingpian was approximately 4 times greater than the ratio after intravenous administration of Bingpian. The plasma concentrations of borneol after the intravenous dose of either Bingpian or synthetic Bingpian declined in a biphasic fashion 
A Extracting solvent, $n$-hexane

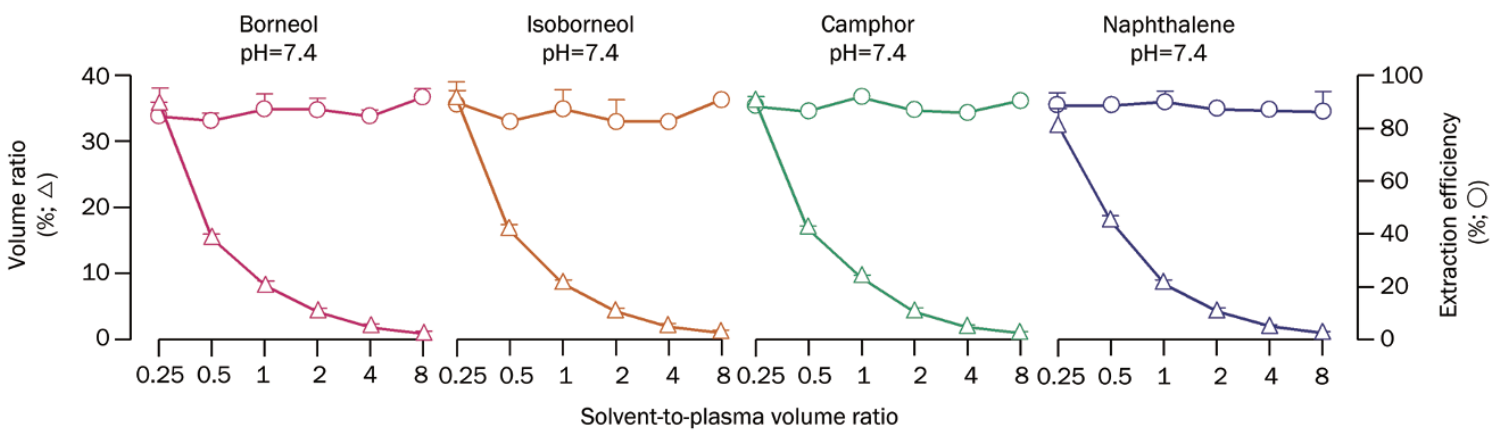

B Extracting solvent, ethyl acetate

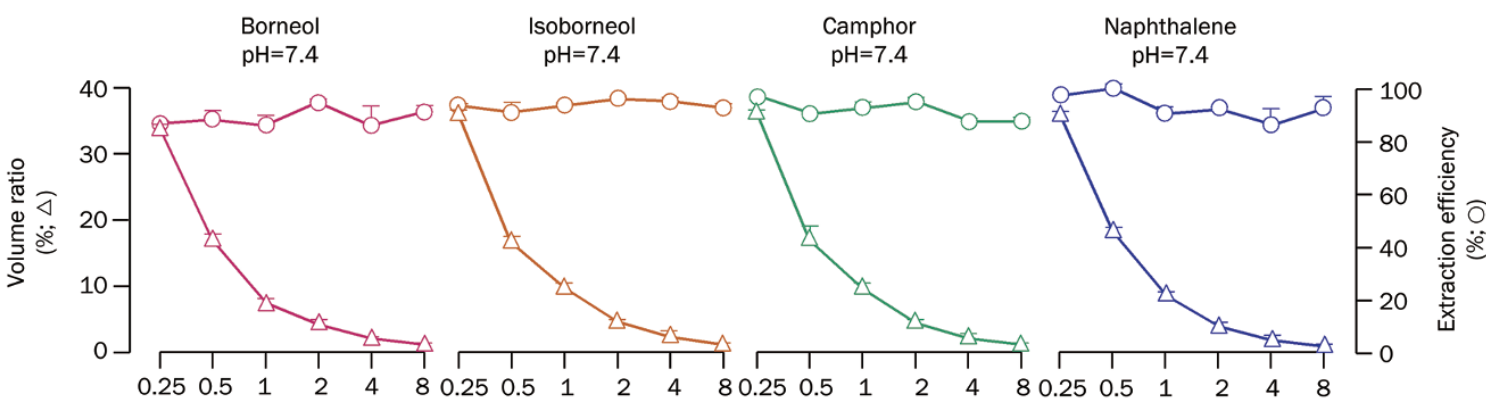

C
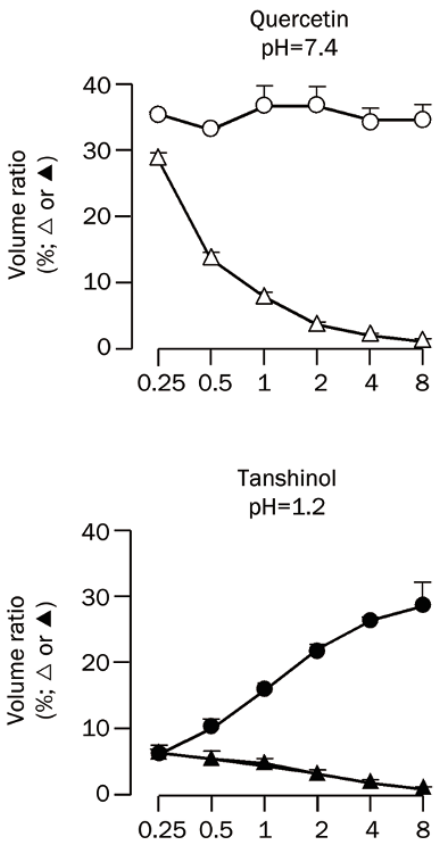

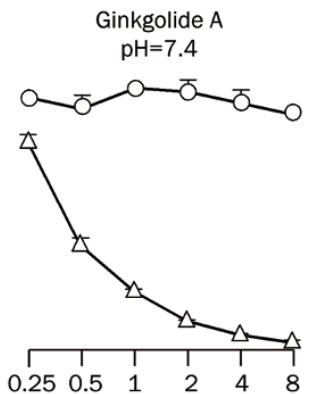

Cinnamic acid $\mathrm{pH}=7.4$

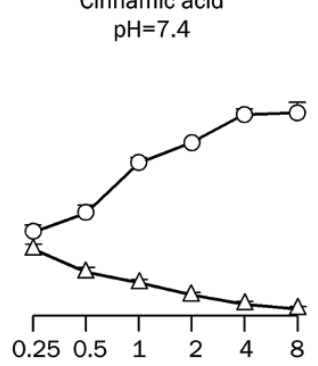

Solvent-to-plasma volume ratio

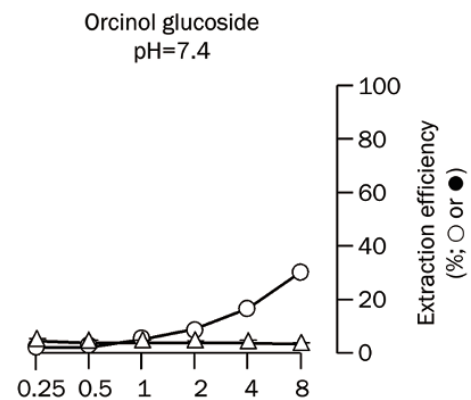

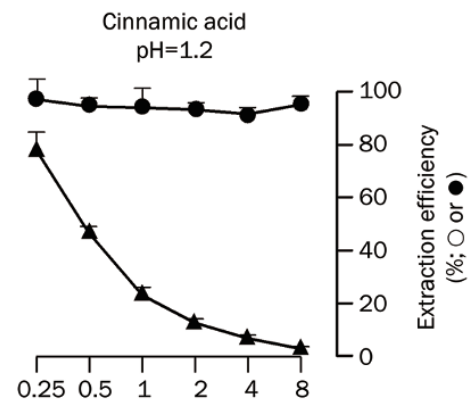

Figure 4. Correlations between the organic solvent-plasma volume ratio ( $\Delta$ or $\boldsymbol{\Delta})$ and extraction efficiency $(O$ or $\boldsymbol{\bullet})$ for various compounds. The nonvolatile compounds quercetin, ginkgolide A, orcinol glucoside, tanshinol, and cinnamic acid were measured by LC-MS/MS. Chromatographic separation was achieved using a Phenomenex Gemini $5 \mu \mathrm{m}$ C18 column $(50 \times 2.0 \mathrm{~mm}$ id; Torrance, CA, USA). The water/acetonitrile/formic acid-based mobile phases were delivered at $0.3 \mathrm{~mL} / \mathrm{min}$ for a binary pulse gradient elution ${ }^{[41]}$. The precursor-to-product ion pairs $\mathrm{m} / \mathrm{z} 407 \rightarrow 351,301 \rightarrow 151$, $331 \rightarrow 123,197 \rightarrow 135$, and $147 \rightarrow 103$ in the negative ESI ion mode were used for selected reaction monitoring of ginkgolide A, quercetin, orcinol glucoside, tanshinol, and cinnamic acid, respectively.

with first mean half-lives $\left(t_{1 / 2-(1)}\right)$ of $0.7-0.8 \mathrm{~h}$ and second mean half-lives $\left(t_{1 / 2-(2)}\right)$ of $8.0-8.5 \mathrm{~h}$, and the plasma concentrations of isoborneol declined rapidly $\left(t_{1 / 2-(1)}, 1.0-1.3 \mathrm{~h}\right)$. The mean total plasma clearance $\left(\mathrm{CL}_{\mathrm{tot}, \mathrm{p}}\right)$ values of borneol were $12.3 \mathrm{~L} \cdot \mathrm{h}^{-1} \cdot \mathrm{kg}^{-1}$ 
Table 2. Long-term stability of the measurement of the plasma extract standard containing borneol, isoborneol, camphor, and the internal standard naphthalene $(250 \mathrm{nmol} / \mathrm{L}$ for each compound). The data are expressed as the mean \pm standard deviation (relative standard deviation).

\begin{tabular}{|c|c|c|c|c|}
\hline Compound & $\begin{array}{l}\text { Response } \\
\qquad\left(\times 10^{4}\right)\end{array}$ & Column efficiency $\left(\times 10^{4}\right)$ & $\begin{array}{l}\text { omatographic paramet } \\
\text { Retention time ( } \mathrm{min})\end{array}$ & Asymmetry factor \\
\hline \multicolumn{5}{|c|}{ Injection Nos: 1-30 } \\
\hline Borneol & $130 \pm 6(4.6 \%)$ & $19.5 \pm 2.4(12.3 \%)$ & $9.18 \pm 0.01$ (0.1\%) & $1.00 \pm 0.13(12.7 \%)$ \\
\hline Isoborneol & $88 \pm 6(6.8 \%)$ & $20.4 \pm 2.5(12.3 \%)$ & $9.02 \pm 0.01(0.1 \%)$ & $1.02 \pm 0.08$ (7.4\%) \\
\hline Camphor & $50 \pm 3(6.0 \%)$ & $24.1 \pm 2.5(10.4 \%)$ & $8.72 \pm 0.01(0.1 \%)$ & $0.97 \pm 0.11(11.7 \%)$ \\
\hline Naphthalene & $142 \pm 7(4.9 \%)$ & $12.2 \pm 1.5(12.3 \%)$ & $9.52 \pm 0.01(0.1 \%)$ & $1.30 \pm 0.19(14.7 \%)$ \\
\hline \multicolumn{5}{|c|}{ Injection Nos: 31-60 } \\
\hline Borneol & $130 \pm 10(7.7 \%)$ & $21.0 \pm 2.1(10.0 \%)$ & $9.21 \pm 0.01$ (0.1\%) & $0.98 \pm 0.08(8.4 \%)$ \\
\hline Isoborneol & $85 \pm 7(8.2 \%)$ & $20.9 \pm 2.0(9.6 \%)$ & $9.04 \pm 0.01(0.1 \%)$ & $1.04 \pm 0.07(6.5 \%)$ \\
\hline Camphor & $49 \pm 3(6.1 \%)$ & $23.1 \pm 3.1(13.4 \%)$ & $8.74 \pm 0.01(0.1 \%)$ & $1.02 \pm 0.10(9.8 \%)$ \\
\hline Naphthalene & $140 \pm 12(8.6 \%)$ & $13.0 \pm 1.7(13.1 \%)$ & $9.54 \pm 0.01(0.1 \%)$ & $1.22 \pm 0.15(11.9 \%)$ \\
\hline \multicolumn{5}{|c|}{ Injection Nos: 61-100 } \\
\hline Borneol & $137 \pm 8(5.8 \%)$ & $21.8 \pm 2.6(12.0 \%)$ & $9.21 \pm 0.01$ (0.1\%) & $0.96 \pm 0.13(13.5 \%)$ \\
\hline Isoborneol & $90 \pm 6(6.7 \%)$ & $20.5 \pm 2.6(12.7 \%)$ & $9.05 \pm 0.01(0.1 \%)$ & $0.97 \pm 0.09$ (9.4\%) \\
\hline Camphor & $49 \pm 4(8.2 \%)$ & $23.0 \pm 3.0(13.0 \%)$ & $8.75 \pm 0.01(0.1 \%)$ & $0.96 \pm 0.12(12.1 \%)$ \\
\hline Naphthalene & $140 \pm 11(7.9 \%)$ & $12.2 \pm 1.7(13.9 \%)$ & $9.55 \pm 0.01(0.1 \%)$ & $1.19 \pm 0.16(13.3 \%)$ \\
\hline
\end{tabular}

Number of theoretic plates $=5.54 \times(\text { retention time } \div \text { peak width at } 1 / 2 \text { height })^{2}$. Peak asymmetry factor was defined as the distance from the center line of the peak to the back slope divided by the distance from the center line of the peak to the front slope, with all measurements made at $10 \%$ of the maximum peak height.

Table 3. Assay accuracy and precision (relative standard deviation) for the measurement of borneol, isoborneol, and camphor in rat plasma. The data are expressed as the mean \pm standard deviation (relative standard deviation).

\begin{tabular}{|c|c|c|c|c|}
\hline \multirow{2}{*}{$\begin{array}{l}\text { Nominal } \\
\text { concentration } \\
\text { (nmol/L) }\end{array}$} & \multicolumn{2}{|c|}{ Within-run ( $n=5)$} & \multicolumn{2}{|c|}{ Between-run ( $n=3$ ) } \\
\hline & $\begin{array}{l}\text { Measured concentration } \\
\qquad(\mathrm{nmol} / \mathrm{L})\end{array}$ & $\begin{array}{l}\text { Accuracy } \\
(\%)\end{array}$ & $\begin{array}{l}\text { Measured concentration } \\
\qquad(\mathrm{nmol} / \mathrm{L})\end{array}$ & $\begin{array}{c}\text { Accuracy } \\
(\%)\end{array}$ \\
\hline \multicolumn{5}{|l|}{ Borneol } \\
\hline 0.98 & $0.88 \pm 0.08$ (9.6\%) & 90 & $0.97 \pm 0.13(13.4 \%)$ & 99 \\
\hline 250 & $270 \pm 17.8(6.6 \%)$ & 108 & $264 \pm 13(4.9 \%)$ & 106 \\
\hline \multicolumn{5}{|l|}{ Isoborneol } \\
\hline 0.98 & $1.07 \pm 0.07(6.5 \%)$ & 109 & $1.04 \pm 0.06(5.6 \%)$ & 106 \\
\hline 250 & $235 \pm 13.9(5.9 \%)$ & 94 & $248 \pm 17(7.0 \%)$ & 99 \\
\hline 16000 & $16800 \pm 1512(9.0 \%)$ & 105 & $16736 \pm 1088(6.5 \%)$ & 105 \\
\hline
\end{tabular}

(for Bingpian) and $8.6 \mathrm{~L} \cdot \mathrm{h}^{-1} \cdot \mathrm{kg}^{-1}$ (for synthetic Bingpian) and the mean $\mathrm{CL}_{\text {tot,p }}$ of isoborneol was $13.7 \mathrm{~L}^{-1} \mathrm{~h}^{-1} \mathrm{~kg}^{-1}$ (for synthetic Bingpian). The mean distribution volumes at steady state $\left(V_{\mathrm{SS}}\right)$ of borneol $(40.2$ and $50.7 \mathrm{~L} / \mathrm{kg}$ for Bingpian and synthetic Bingpian, respectively) and isoborneol $(13.0 \mathrm{~L} / \mathrm{kg}$ for synthetic Bingpian) exceeded the reported volume of rat total body water $(0.67 \mathrm{~L} / \mathrm{kg})^{[38]}$, suggesting that borneol and isoborneol tended to bind to the tissue components. Borneol was not transformed to isoborneol in rats, which was indicated by the lack of isoborneol detected in plasma after the administration of Bingpian.

\section{Discussion}

The use of herbal therapies is escalating worldwide. In correlating the administration of herbal medicines with their beneficial effects, it is important to understand the absorption, 

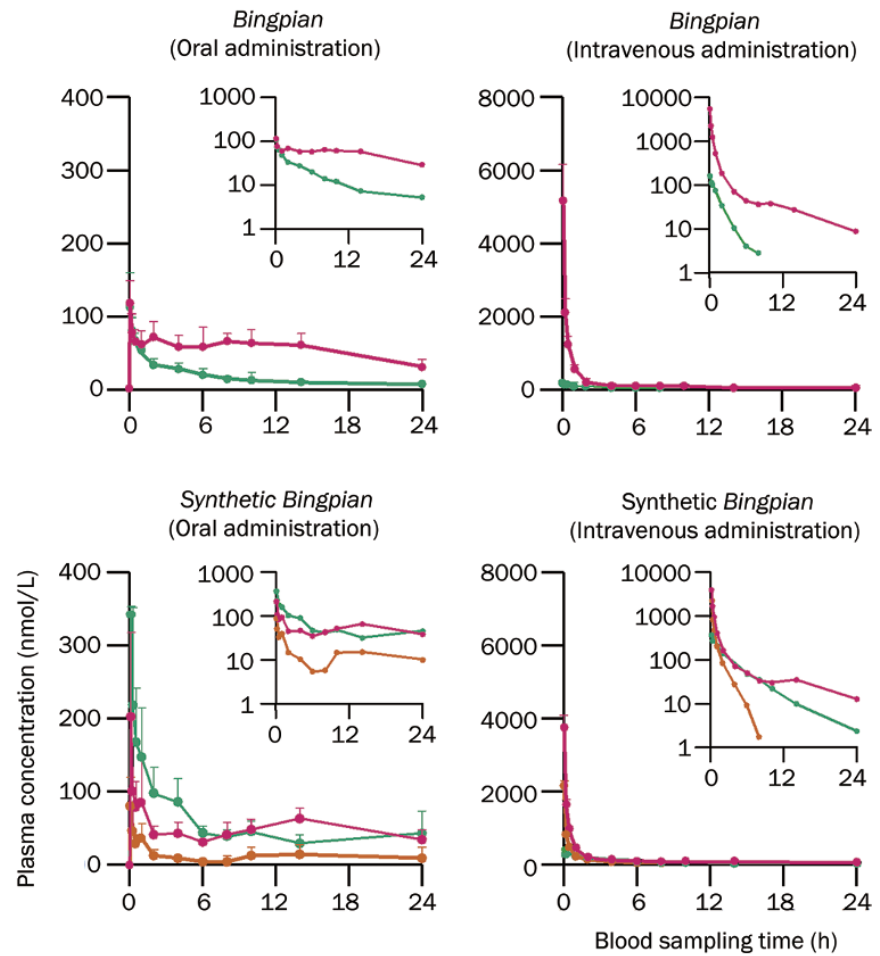

Fufang Danshen $T$

(Oral administration)

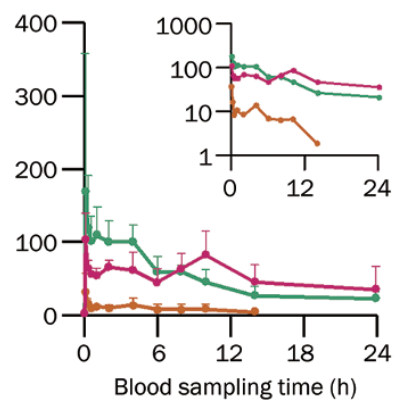

Figure 5. Rat plasma concentration-time profiles of borneol, isoborneol, and their metabolite camphor after an oral dose of Bingpian (20 $\mathrm{mg}$ borneol/kg), synthetic Bingpian (20 mg borneol+isoborneol/kg), or Fufang-Danshen tablets (containing synthetic Bingpian; $20 \mathrm{mg}$ borneol+isoborneol/kg) or an intravenous dose of Bingpian (5 mg borneol/kg) or synthetic Bingpian (5 mg borneol+isoborneol/kg).

disposition, and pharmacokinetics of their active ingredients after dosing. In addition to nonvolatile ingredients, many volatile constituents are also pharmacologically important for herbal therapies. However, the assays available for measuring volatile compounds have not been very successful in supporting the associated pharmacokinetic studies. Herein, we developed a reliable assay for the sensitive measurement of borneol, isoborneol, and their metabolite camphor in plasma to support a pharmacokinetic study of Bingpian. The high sensitivity of this assay was achieved by using a liquid-liquid microextraction technique in concert with PTV-based LVI of the organic extract for GC-MS, which was 33-330 times higher than the sensitivity of earlier reported analytical methods for
Bingpian $^{[27-33]}$. To our knowledge, this is the first time that liquid-liquid microextraction has been combined with PTVbased LVI and developed to measure the concentrations of volatile herbal compounds in complex biomatrices. Our study provides a simple, effective solution to the analytical problem hampering the implementation of pharmacokinetic studies of herbal medicines containing volatile ingredients of pharmacological importance.

Several liquid-liquid microextraction techniques such as single-drop microextraction, hollow fiber liquid phase microextraction, and dispersive liquid-liquid microextraction have been developed ${ }^{[39]}$. However, these techniques have some disadvantages, including tedious and labor-consuming operation, the requirement of special equipment, and applicability to a limited range of analytes. Recently, Serrano et al developed a similar liquid-liquid microextraction combined with PTVbased LVI for water analysis to measure haloacetaldehyde concentrations in swimming pool water ${ }^{[40]}$. In this current study, the developed method of liquid-liquid microextraction combined with PTV-based LVI is quite feasible and can be routinely used for pharmacokinetic studies of Bingpian and the associated herbal products. The utilization ratio of the injection volume $(20 \mu \mathrm{L})$ to the extracting solvent volume (35 $\mu \mathrm{L})$ was high $(57 \%)$. Our work is an important addition to previous studies associated with miniaturized liquid-liquid extraction techniques because we have addressed the application of this technique in the analysis of volatile and nonvolatile compounds, which could be predicted according to the analytes' $\log D$ and $\mathrm{p} K_{\mathrm{a}}$. Compounds with $\log D>-0.2$ appeared to be more suitable for such liquid-liquid microextraction.

Acute matrix-induced response enhancement has been observed for GC-based analyses of pesticide residues in fatty foods ${ }^{[34,35]}$. The matrix protects the analytes from both adsorption and alterations during transfer from the injector (especially in the injection liner) to the capillary column. The matrix effect results in the response of the analyte from a matrix sample being higher than that from a matrix-free solution containing the compound at the same concentration. In this study, the acute matrix-induced response enhancement was almost negligible for the measurement of plasma concentrations of borneol, isoborneol, camphor, and the internal standard naphthalene. In addition, the compound responses and the chromatographic behaviors did not change significantly during and after 100 successive injections of the plasma extract standard, indicating good tolerance of the PTV injector and the GC column for long-term use with plasma samples. It has been reported that polar compounds (containing phosphate, hydroxyl, amino, imidazole, benzimidazole, carbamate, and urea functional groups), as well as strong acids and/or bases, are more susceptible to matrix-induced enhancement ${ }^{[35]}$. Borneol, isoborneol, camphor, and naphthalene are nonpolar and neutral compounds, which might explain the observed negligible matrix effects on the GC-MS-based measurement of the analytes.

In summary, a reliable GC-MS-based assay for the sensitive measurement of plasma concentrations of borneol, isoborneol, 
Table 4. Plasma pharmacokinetics of borneol, isoborneol, and camphor in rats receiving Bingpian, synthetic Bingpian, or Fufang-Danshen tablets. The data are expressed as the mean \pm standard deviation (relative standard deviation).

\begin{tabular}{ccccccccccc}
\hline Compound & $C_{\max }$ or $C_{5 \min }$ & $T_{\text {peak }}$ & $\mathrm{AUC}_{0-\mathrm{t}}$ & $\mathrm{AUC}_{0-\infty}$ & $t_{1 / 2-(1)}$ & $t_{1 / 2-(2)}$ & $\mathrm{MRT}$ & $\mathrm{CL}_{\text {tot, p }}$ & $V_{\mathrm{SS}}$ & $F$ \\
& $(\mathrm{nmol} / \mathrm{L})$ & $(\mathrm{h})$ & $(\mathrm{h} \cdot \mathrm{nmol} / \mathrm{L})$ & $(\mathrm{h} \cdot \mathrm{nmol} / \mathrm{L})$ & $(\mathrm{h})$ & $(\mathrm{h})$ & $(\mathrm{h})$ & $\left(\mathrm{L} \cdot \mathrm{h}^{-1} \cdot \mathrm{kg}^{-1}\right)$ & $(\mathrm{L} / \mathrm{kg})$ & $(\%)$
\end{tabular}

Natural Bingpian at an oral dose of $20 \mathrm{mg}$ borneol $/ \mathrm{kg}$

$\begin{array}{lllll}\text { Borneol } & 116 \pm 39 & 0.083 \pm 0 & 1266 \pm 307 & 1558 \pm 413\end{array}$

$\begin{array}{lllcr}\text { Corneol } & 116 \pm 39 & 0.083 \pm 0 & 1266 \pm 307 & 1558 \pm 413 \\ \text { Camphor } & 108 \pm 50 & 0.083 \pm 0 & 362 \pm 24 & 432 \pm 106\end{array}$

$\begin{array}{rrr}- & - & 10.6 \pm 0.8 \\ - & - & 6.1 \pm 1.8\end{array}$

$\begin{array}{ccc} & & \\ - & - & 11.6 \pm 2.8 \\ - & - & -\end{array}$

Natural Bingpian at an intravenous dose of $5 \mathrm{mg}$ borneol/kg

$\begin{array}{lcccccccccc}\text { Borneol } & 5122 \pm 1030 & - & 2724 \pm 517 & 2825 \pm 583 & 0.7 \pm 0.1 & 8.5 \pm 2.0 & 2.5 \pm 0.8 & 12.3 \pm 2.5 & 40.2 \pm 12.0 & - \\ \text { Camphor } & 149 \pm 17 & - & 207 \pm 77 & 210 \pm 78 & 1.3 \pm 0.5 & - & 1.6 \pm 0.5 & - & - & -\end{array}$

Synthetic Bingpian at an oral dose of $20 \mathrm{mg}$ borneol+isoborneol/kg

$\begin{array}{lccrr}\text { Borneol } & 201 \pm 114 & 0.083 \pm 0 & 1209 \pm 105 & 1726 \pm 354 \\ \text { Isoborneol } & 84 \pm 34 & 0.39 \pm 0.53 & 310 \pm 140 & 331 \pm 135 \\ \text { Camphor } & 354 \pm 15 & 0.14 \pm 0.10 & 1311 \pm 461 & 1471 \pm 547\end{array}$

Synthetic Bingpian at an intravenous dose of $5 \mathrm{mg}$ borneol+isoborneol/kg

\begin{tabular}{|c|c|c|c|c|c|c|c|c|c|c|}
\hline Borneol & $3691 \pm 374$ & - & $2375 \pm 230$ & $2576 \pm 265$ & $0.8 \pm 0.1$ & $8.0 \pm 2.9$ & $3.6 \pm 0.7$ & $8.6 \pm 0.9$ & $50.7 \pm 16.9$ & - \\
\hline Isoborneol & $2113 \pm 141$ & - & $893 \pm 83$ & $902 \pm 74$ & $1.0 \pm 0.1$ & - & $0.9 \pm 0.2$ & $13.7 \pm 1.4$ & $13.0 \pm 1.3$ & - \\
\hline Camphor & $349 \pm 24$ & - & $984 \pm 172$ & $1011 \pm 161$ & $2.5 \pm 3.1$ & - & $4.1 \pm 0.7$ & - & - & - \\
\hline \multicolumn{11}{|c|}{ Fufang-danshen tablets at an oral dose of $20 \mathrm{mg}$ borneol+isoborneol/kg } \\
\hline Borneol & $109 \pm 24$ & $1.39 \pm 2.26$ & $1349 \pm 327$ & $1612 \pm 262$ & - & - & $12.0 \pm 1.2$ & - & - & $14.2 \pm 3.4$ \\
\hline Isoborneol & $35 \pm 21$ & $1.39 \pm 2.26$ & $101 \pm 64$ & $105 \pm 71$ & - & - & $5.3 \pm 2.4$ & - & - & $2.8 \pm 1.8$ \\
\hline Camphor & $201 \pm 160$ & $2.69 \pm 2.26$ & $1128 \pm 297$ & $1456 \pm 589$ & - & - & $7.8 \pm 1.2$ & - & - & - \\
\hline
\end{tabular}

$C_{\text {max }}$, maximum plasma concentration after oral dose; $C_{5}$ min, plasma concentration at 5 min after intravenous dose; $T_{\text {peak }}$, time taken to achieve peak concentration; $t_{1 / 2}$, elimination half-life; $\mathrm{AUC}_{0 \rightarrow t}$, area under concentration-time curve up to the time of last measurable concentration; $\mathrm{AUC}_{0 \rightarrow \infty}$, $\mathrm{AUC}_{0 \rightarrow \mathrm{t}}$ extrapolated to infinity; $\mathrm{MRT}$, mean residence time; $\mathrm{CL}_{\mathrm{tot}, \mathrm{p}}$, total plasma clearance; $\mathrm{V}_{\mathrm{sS}}$, distribution volume at steady state.

and their metabolite camphor was developed, primarily by using liquid-liquid microextraction in concert with PTV-based LVI of the organic extract. The application of the miniaturized liquid-liquid extraction technique could be extended to the measurement of other volatile compounds and many nonvolatile medicinal compounds in biomatrices, which can be predicted according to the $\log D$ and $\mathrm{p} K_{\mathrm{a}}$ of the analytes. On the basis of this newly developed assay, it was observed that, in rats, isoborneol was more likely to be metabolized into camphor than borneol.

\section{Acknowledgements}

This study was financially supported by the National Natural Science Fundation of China for Distinguished Young Scholars (Grant 30925044), the National Basic Research Program of China (Grant 2012CB518403), and the National Science and Technology Major Project of China "Key New Drug Creation and Manufacturing Program" (Grant 2009ZX09304-002).

\section{Author contribution}

Chuan LI, Chen CHENG, and Yan SUN designed the research; Chen CHENG, Xin-wei LIU, Fei-fei DU, Mei-juan LI, Fang XU, Feng-qing WANG, and Yang LIU, performed the research; Chuan LI, Chen CHENG, Xin-wei LIU, and Yan SUN analyzed data; Chuan LI and Chen CHENG wrote the paper.

\section{References}

1 Aoshima H, Hamamoto $\mathrm{K}$. Potentiation of $\mathrm{GABA}_{\mathrm{A}}$ receptors expressed in Xenopus oocytes by perfume and phytoncid. Biosci Biotechnol Biochem 1999; 63: 743-8.

2 Mühlbauer RC, Lozano A, Palacio S, Reinli A, Felix R. Common herbs, essential oils, and monoterpenes potently modulate bone metabolism. Bone 2003; 32: 372-80.

3 Huang LS, Gu YF, Li H. Advances in herbal volatile oil and aromatic herbs. China J Chin Mater Med 2009; 34: 1606-11. Chinese.

4 Miguel MG. Antioxidant and anti-inflammatory activities of essential oils: a short review. Molecules 2010; 15: 9252-87.

5 Liang YZ, Xie PS, Chan K. Quality control of herbal medicines. J Chromatogr B 2004; 812: 53-70.

6 Li P, Qi LW, Liu EH, Zhou JL, Wen XD. Analysis of Chinese herbal medicines with holistic approaches and integrated evaluation models. Trends Anal Chem 2008; 27: 66-77.

7 Vogt W, Jacob K, Ohnesorge AB, Obwexer HW. Capillary gas chromatographic injection system for large sample volumes. J Chromatogr 1979; 186: 197-205.

8 Ŝtajnbaher D, Zupančič-Kralj L. Optimization of programmable temperature vaporizer-based large volume injection for determination of pesticide residues in fruits and vegetables using gas chromatography-mass spectrometry. J Chromatogr A 2008; 1190: 316-26.

9 "Zhonghua Bencao" Commission of State Administration of Traditional Chinese Medicine of the People's Republic of China. Zhonghua Bencao (Encyclopedia of Chinese Materia Medica); book 3. Shanghai: Shanghai Scientific and Technical Publishers; 1999. p 551-5 (natural 
Bingpian).

10 Chinese Pharmacopoeia Commission. Pharmacopoeia of the People's Republic of China (English Edition 2010); v 1. Beijing: China Medical Science Press; 2010. p 73-4 (natural Bingpian), 72-3 (synthetic Bingpian), and 684-6 (Fufang-danshen tablets).

11 Silva-Filho JC, Oliveira NNPM, Arcanjo DDR, Quitans-Júnior LJ, Cavalcanti SCH, Santos MRV, et al. Investigation of mechanisms involved in (-)-borneol-induced vasorelaxant response on rat thoracic aorta. Basic Clin Pharmacol Toxicol 2011; 110: 171-7.

$12 \mathrm{Li} \mathrm{YH,} \mathrm{Sun} \mathrm{XP,} \mathrm{Zhang} \mathrm{YQ,} \mathrm{Wang} \mathrm{NS.} \mathrm{The} \mathrm{antithrombotic} \mathrm{effect} \mathrm{of}$ borneol related to its anticoagulant property. Am J Chin Med 2008; 36: 719-27.

13 Tian LL, Zhou Z, Zhang Q, Sun YN, Li CR, Cheng CH, et al. Protective effect of $( \pm$ )isoborneol against 6-OHDA-induced apoptosis in SH-SY5Y cells. Cell Physiol Biochem 2007; 20: 1019-32.

14 Liu R, Zhang L, Lan X, Li L, Zhang TT, Sun JH, et al. Protection by borneol on cortical neurons against oxygen-glucose deprivation/ reperfusion: involvement of anti-oxidation and anti-inflammation through nuclear transcription factor kappaB signaling pathway. Neuroscience 2011; 176: 408-19.

15 Park TJ, Park YS, Lee TG, Ha HJ, Kim KT. Inhibition of acetylcholinemediated effects by borneol. Biochem Pharmacol 2003; 65: 83-90.

16 Granger RE, Campbell EL, Johnston GAR. (+)- and (-)-borneol: efficacious positive modulator of GABA action at human recombinant $\alpha_{1} \beta_{2} \gamma_{2 L} G_{A B A}$ receptors. Biochem Pharmacol 2005; 69: 1101-11.

17 Chen TF, Lin SG, Chen LX, Jiang GF, Liang ZY, Yang M, et al. Enhancement of absorption of tetramethylpyrazine by synthetic borneol. Acta Pharmacol Sin 1990; 11: 42-4.

18 Cheng G, Wu SR, Feng Y. Studies on the effects of borneol on the pharmacokinetics of rifampicin. J Shenyang Pharm Univ 2001; 18 : 398-401. Chinese.

19 Liu QD, Liang MR, Chen ZX, Feng MR, Zhao P. The influence of borneol on the passing of gentamycin through blood-brain barrier. J Guangzhou College Tradit Chin Med 1994; 11: 37-40. Chinese.

20 Dong XZ, Tang XA, Qiu QH, Xu HB. Study on the auto-action of borneol assisting the penetration of DDP across BBB. Chin Pharm J 2002; 37 : 275-7. Chinese.

21 Cai Z, Hou SX, Li YB, Zhao BB, Yang ZX, Xu SG, et al. Effect of borneol on the distribution of gastrodin to the brain in mice via oral administration. J Drug Target 2008; 16: 178-84.

22 Jiang XF, Zou JL, Yuan YM, Law FCP, Qiao YJ, Yao MC. Preliminary study: biotransformation of borneol to camphor in mice, rats and rabbits. Mode Tradit Chin Med Mater Med 2008; 10: 27-36.

23 Manoguerra AS, Erdman AR, Wax PM, Nelson LS, Caravati EM, Cobaugh DJ, et al. Camphor poisoning: an evidence-based practice guideline for out-of-hospital management. Clin Toxicol 2006; 44: 357-70.

24 Lu T, Yang JY, Gao XM, Chen P, Du FF, Sun Y, et al. Plasma and urinary tanshinol from Salvia miltiorrhiza (Danshen) can be used as pharmacokinetic markers for cardiotonic pills, a cardiovascular herbal medicine. Drug Metab Dispos 2008; 36: 1578-86.

25 Liu HF, Yang JL, Du FF, Gao XM, Ma XT, Huang YH, et al. Absorption and disposition of ginsenosides after oral administration of Panax notoginseng extract to rats. Drug Metab Dispos 2009; 37: 2290-8.

26 Hu ZY, Yang JL, Cheng C, Huang YH, Du FF, Wang FQ, et al. Combinatorial metabolism notably affects human systemic exposure to ginsenosides from orally administered extract of Panax notoginseng roots (Sanqi). Drug Metab Dispos 2013; 41: 1457-69.

27 Chen Q, Li SM, Wang W. GC-MS simultaneous determination of borneol and paeonol in mice plasma. Chin J Pharm Anal 2006; 26 : 592-4. Chinese.

28 Huang TL, Ye SM, Ou WP, Mi SQ. Comparative study of the pharmacokinetics of borneolum syntheticum and borneol in herbal preparations. Tradit Chin Drug Res Clin Pharmacol 2006; 17: 265-7. Chinese.

29 Guo J, Huang X, Wang LL, Meng H, Zhang L, Ren P. Synchro-determination of borneol and tetramethyl pyrazine in plasma by GC-FID for volunteers administered with Suxiao Jiuxin Wan. Chin Tradit Herb Drugs 2003; 34: 730-2. Chinese.

30 Song HT, Guo T, Zhang XH, Kang J, Leng YX, Zhang RH. Determination of borneol in human plasma by capillary gas chromatography. Pharm J Chin PLA 2003; 19: 12-5. Chinese.

31 Xiao YY, Ping QN, Chen ZP. A simple gas chromatographic method for the simultaneous determination and pharmacokinetic study of tetramethylpyrazine phosphate and borneol in mouse plasma and brain tissue after oral administration of the Fufang tetramethylpyrazine phosphate tablets. J Chromatogr Sci 2008; 46: 395-400.

32 Xu XF, Li YB, Hou JP, Zhang SZ, Xu YY, Wang Y, et al. Pharmacokinetic study of borneol and menthol in rats after oral administration of qingyan drop pills. Planta Med 2011; 77: 1600-4.

33 Zhao JY, Lu Y, Du SY, Song X, Bai J, Wang Y. Comparative pharmacokinetic studies of borneol in mouse plasma and brain by different administrations. J Zhejiang Univ-Sci B (Biomed \& Biotechnol) 2012; 13: 990-6. Chinese.

34 Erney DR, Gillespie AM, Gilvydis DM. Explanation of the matrixinduced chromatographyic response enhancement of organophosphorus pesticides during open tubular column gas chromatography with splitless or hot on-column injection and flame photometric detection. J Chromatogr A 1993; 638: 57-63.

35 Poole CF. Matrix-induced response enhancement in pesticide residue analysis by gas chromatography. J Chromatogr A 2007; 1158: 241-50.

36 Matuszewski BK, Constanzer ML, Chavez-Eng CM. Strategies for the assessment of matrix effect in quantitative bioanalytical methods based on HPLC-MS/MS. Anal Chem 2003; 75: 3019-30.

37 Guo B, Li C, Deng ZP, Chen SX, Ji ZH, Zhang JW, et al. A new method for measurement of (-)-sophocarpine, a candidate therapeutic for viral myocarditis, in plasma: application to a toxicokinetic study in beagle dogs. Rapid Commun Mass Spectrom 2005; 19: 2840-8.

38 Davies B, Morris T. Physiological parameters in laboratory animals and humans. Pharm Res 1993; 10: 1093-5.

39 Nováková L, VIcková H. A review of current trends and advances in modern bio-analytical methods: chromatography and sample preparation. Anal Chim Acta 2009; 656: 8-35.

40 Serrano M, Salva M, Gallego M. Micro liquid-liquid extraction combined with large-volume injection gas chromatography-mass spectrometry for the determination of haloacetaldehydes in treated water. J Chromatogr A 2011; 1218: 8295-302.

41 Wang L, Sun Y, Du FF, Niu W, Lu T, Kan JM, et al. 'LC-electrolyte effects' improve the bioanalytical performance of liquid chromatography/tandem mass spectrometric assays in supporting drug discovery pharmacokinetic study. Rapid Commun Mass Spectrom 2007; 21: 2573-84. 